\title{
Alkene anti-Dihydroxylation with Malonoyl Peroxides
}

\author{
Carla Alamillo-Ferrer, ${ }^{+}$Stuart C. Davidson, ${ }^{+}$Michael J. Rawling, ${ }^{+}$Natalie H. Theodoulou, ${ }^{+,}$Matthew Campbell, ${ }^{+}$ \\ Philip G. Humphreys, ${ }^{\ddagger}$ Alan R. Kennedy ${ }^{+}$and Nicholas C. O. Tomkinson ${ }^{+, *}$
}

+WestCHEM, Department of Pure and Applied Chemistry, Thomas Graham Building, University of Strathclyde, 295 Cathedral Street, Glasgow, G1 1XL, U.K.

${ }^{\ddagger}$ GlaxoSmithKline Medicines Research Centre, Gunnels Wood Road, Stevenage, SG1 2NY, U.K.

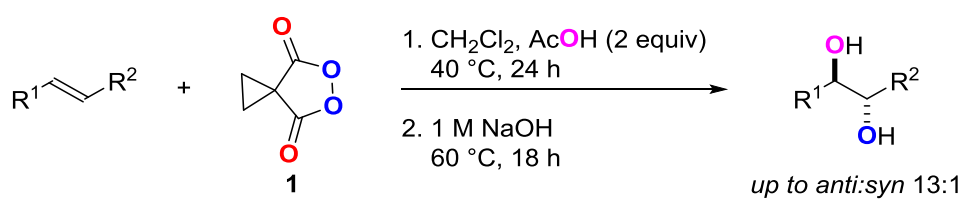

\begin{abstract}
Malonoyl peroxide 1, prepared in a single step from the commercially available diacid, is an effective reagent for the antidihydroxylation of alkenes. Reaction of $\mathbf{1}$ with an alkene in the presence of acetic acid at $40{ }^{\circ} \mathrm{C}$ followed by alkaline hydrolysis leads to the corresponding diol (35-92\%) with up to 13:1 anti-selectivity. A mechanism consistent with experimental findings is proposed which accounts for the selectivity observed.
\end{abstract}

The prevalence of 1,2-diols in natural products and biologically active molecules together with the synthetic versatility of this functionality has provided the motivation to discover new methods for their preparation. Within this toolkit, of particular note are approaches for the dihydroxylation of alkenes which have delivered innovation and advancement in methodology development. ${ }^{1}$ Whilst a number of procedures have been developed for the syndihydroxylation of alkenes using both metal-catalyzed ${ }^{2}$ and metalfree procedures, ${ }^{3}$ introduction of the anti-1,2-diol has received significantly less attention. ${ }^{4}$

The majority of methods to access anti-1,2-diols involve the ring opening of epoxides. ${ }^{5}$ The required epoxides can be accessed in an asymmetric manner via processes including the Sharpless, ${ }^{6}$ Jacobsen ${ }^{7}$ and $\mathrm{Shi}^{8}$ procedures. Regio- and stereoselective reaction of the epoxides with oxygen nucleophiles then leads to the antidiol. ${ }^{9}$ More recently, List has reported an organocatalytic asymmetric hydrolysis of meso-epoxides, providing a useful alternative to these well-established methods. ${ }^{4 \mathrm{~b}}$ Alexanian et al. have developed both intra- ${ }^{10}$ and intermolecular ${ }^{11}$ methods for the stereoselective anti-dioxygenation of alkenes using hydroxamic acids and oxygen as the sources of the new $\mathrm{C}-\mathrm{O}$ bonds providing the products in good yield and moderate selectivities. A more established direct method to access anti-1,2-diols from alkenes is the Prévost reaction $^{12}$ which proceeds through hypervalent iodine intermediates. ${ }^{13}$

It has been established that malonoyl peroxides can be used for the syn-dihydroxylation of alkenes. ${ }^{14}$ For example, treatment of stilbene 2 with 1.2 equivalents of peroxide $\mathbf{1}$ in the presence of water followed by basic hydrolysis leads to the syn-diol 3 (86\%; syn:anti 33:1) (Scheme 1). Within this manuscript we show that malonoyl peroxides can also be used in a complementary procedure to secure the anti-1,2-diol. ${ }^{15}$
Scheme 1. Malonoyl peroxides in the dioxygenation of alkenes.

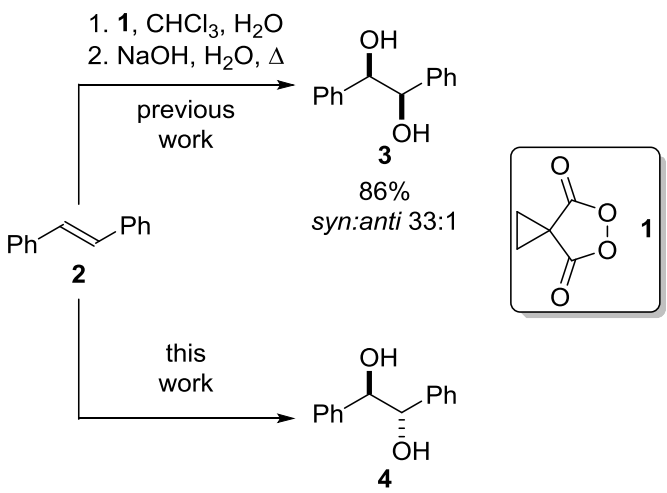

The mechanistic pathway determined for the syndihydroxylation of alkenes with malonoyl peroxides is outlined in Scheme $2 .{ }^{16}$ Reaction of alkene $\mathbf{2}$ with peroxide $\mathbf{1}$ leads to zwitterionic species 5 which can cyclize to give either the 7-membered ring 6 as a single stereoisomer (minor) or the dioxonium species 7 (major). Hydrolysis of 7 through addition of water at carbon $\mathrm{A}$ leads to the ester 10. Basic hydrolysis of a crude mixture of 6 and 10 provides the syn-diol 3 in excellent yield and outstanding selectivity (86\%; syn:anti33:1).

Reactive species related to the dioxonium 7 have been described as intermediates within the Prévost reaction. ${ }^{17}$ Addition of a carboxylic acid to this class of compound leads to the corresponding anti-dioxygenated species. We wished to discover if a similar reaction pathway could be developed whereby addition of acetic acid to 7 at carbon $\mathbf{B}$ would lead to diester $\mathbf{8}$, hydrolysis of which would provide the anti-diol product 4 . Herein we describe the development of this procedure providing a simple and effective perox- 
ide mediated metal-free method for the anti-dihydroxylation of

alkenes.

Scheme 2. Mechanistic course of dioxygenation with malonoyl peroxide 1.<smiles>O=C1OOC(=O)C12CC2</smiles>

1 (1.2 equiv)<smiles>C(=Cc1ccccc1)c1ccccc1</smiles>

2<smiles>CCC</smiles><smiles>O=[N+](O)C#CCCCCCC(O)C(O)c1ccccc1</smiles>

4

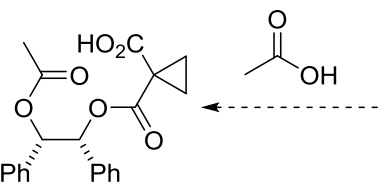

8

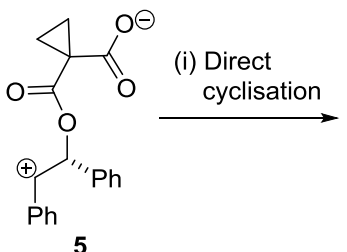

5

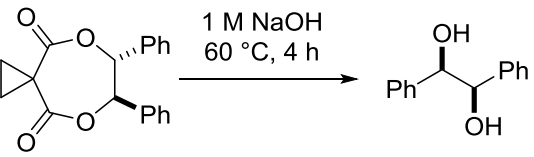

$6(14 \%)$

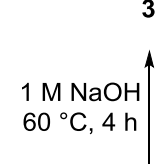

3
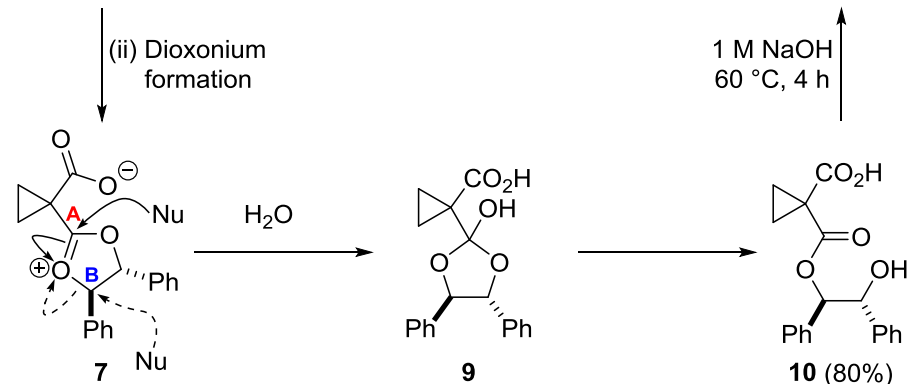

9

Our investigations began by replacement of the water used in the published syn-dihydroxylation procedure with acetic acid (Table 1). Reaction of stilbene 2 with 1.2 equivalents of peroxide 1 in the presence of one equivalent of acetic acid $\left(40^{\circ} \mathrm{C}, 24 \mathrm{~h}\right)$ followed by basic hydrolysis gave the diol 4 (entry 1; 78\%, 1:2 anti:syn). Although this ratio was low in favor of the syn-diastereoisomer it was significantly different to the ratio observed in the presence of water (1:33, anti:syn) and suggested our mechanistic hypothesis was correct such that the stereochemical outcome of the reaction could be reversed by changing additive. Performing the reaction in neat acetic acid rendered the reaction anti-selective (entry 2; 66\%, 2:1 anti:syn) and drying the acetic acid improved this ratio further (entry 3; 43\%, 4:1 anti:syn). A brief examination of reaction medium (entries 4-6) showed less polar solvents improved the anti:syn ratio further with dichloromethane emerging as the best option (entry 4; 78\%, 6:1 anti:syn). Altering the equivalents of acid and peroxide (entries 7-13) led to an optimized set of reaction conditions which provided the product in excellent yield and good selectivity (entry 11; 92\%, 7:1 anti:syn). Conducting the reaction in the presence of acetic anhydride to sequester any water present in the reaction mixture led to no significant change in the stereochemical outcome (entry 10;77\%, 6:1 anti:syn). It also proved possible to conduct the reaction in the presence of alternative acids such as benzoic acid (entry 14; 75\%, 6:1 anti:syn) and 4-methoxybenzoic acid (entry 15; 68\%, 6:1 anti:syn) neither of which had a notable influence on the reaction outcome.

Having developed effective reaction conditions for the antidihydroxylation procedure we turned our attention to exploring the substrate scope (Table 2 ). The reaction proceeded well with alternative stilbene derivatives (entries 2, 3 and 6), delivering the products in high yield and up to 6:1 anti:syn selectivity. Use of cisstilbene as a substrate gave the product in reasonable yield but with low levels of selectivity (entry 4; 79\% yield, 4:3 anti:syn) suggesting that for this product a more effective strategy would be to perform a syn-dihydroxylation on the trans-alkene substrate. ${ }^{14 a}$ The reaction was also effective for a number of styrene derivatives (entries 5 and $7-15)$. $\beta$-Methylstyrene provided access to the anti-product 15 in excellent yield and acceptable selectivity (entry 7; 89\%, anti:syn $4: 1)$. Substituents on the aromatic ring were tolerated (entries $8-$ 11), however, electron withdrawing substituents significantly slowed down the reaction. For example, a styrene derivative with a nitro group on the aromatic ring reached $45 \%$ completion $(35 \%$ yield) after $24 \mathrm{~h}$, the mass balance of the reaction being accounted for by unreacted starting material (entry 10). Increasing the steric demands of both the aromatic (entry $11 ; 90 \%$, anti:syn 5:1) and aliphatic (entry 12;77\%, anti:syn 4:1) alkene substituents had little effect on the stereochemical outcome of the transformation.

Table 1. Optimization of anti-dihydroxylation. ${ }^{a}$

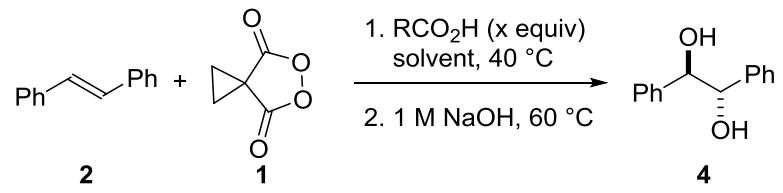

\begin{tabular}{ccccccc} 
entry & solvent $\mathrm{RCO}_{2} \mathrm{H}$ (equiv) & $\mathrm{R}$ & \multicolumn{1}{c}{ (equiv) } & yield $(\%)^{b}$ & anti:syn \\
$1^{d}$ & $\mathrm{CHCl}_{3}$ & 1 & $\mathrm{Me}$ & 1.2 & 78 & $1: 2$ \\
$2^{d}$ & $\mathrm{AcOH}$ & 35 & $\mathrm{Me}$ & 1.2 & 66 & $2: 1$ \\
3 & $\mathrm{AcOH}$ & 35 & $\mathrm{Me}$ & 1.2 & 43 & $4: 1$ \\
4 & $\mathrm{CH}_{2} \mathrm{Cl}_{2}$ & 1 & $\mathrm{Me}$ & 1.2 & 78 & $6: 1$ \\
5 & $\mathrm{PhMe}_{6}$ & 1 & $\mathrm{Me}$ & 1.2 & 72 & $4: 1$ \\
6 & $\mathrm{THF}$ & 1 & $\mathrm{Me}$ & 1.2 & 43 & $1: 1$ \\
7 & $\mathrm{CH}_{2} \mathrm{Cl}_{2}$ & 2 & $\mathrm{Me}$ & 1.2 & 72 & $7: 1$ \\
8 & $\mathrm{CH}_{2} \mathrm{Cl}_{2}$ & 3 & $\mathrm{Me}$ & 1.2 & 77 & $5: 1$ \\
9 & $\mathrm{CH}_{2} \mathrm{Cl}_{2}$ & 5 & $\mathrm{Me}$ & 1.2 & 75 & $5: 1$ \\
$10^{e}$ & $\mathrm{CH}_{2} \mathrm{Cl}_{2}$ & 2 & $\mathrm{Me}$ & 1.2 & 77 & $6: 1$ \\
11 & $\mathrm{CH}_{2} \mathrm{Cl}_{2}$ & 2 & $\mathrm{Me}$ & 1.5 & 92 & $7: 1$ \\
12 & $\mathrm{CH}_{2} \mathrm{Cl}_{2}$ & 3 & $\mathrm{Me}$ & 1.5 & 95 & $6: 1$ \\
13 & $\mathrm{CH}_{2} \mathrm{Cl}_{2}$ & 3 & $\mathrm{Me}$ & 2.0 & 91 & $6: 1$ \\
14 & $\mathrm{CH}_{2} \mathrm{Cl}_{2}$ & 2 & $\mathrm{Ph}$ & 1.5 & 75 & $6: 1$ \\
15 & $\mathrm{CH}_{2} \mathrm{Cl}_{2}$ & 2 & $4-\mathrm{MeOC}_{6} \mathrm{H}_{4} 1.5$ & 68 & $6: 1$
\end{tabular}

${ }^{a}$ All reactions performed in duplicate with stilbene $(1 \mathrm{mmol})$ at 0.5 $\mathrm{M}$ concentration; 'Isolated yield after column chromatography; ${ }^{c}$ Determined by ${ }^{1} \mathrm{H}$ NMR spectroscopy on crude reaction mixture; ${ }^{d}$ Bench acetic acid was used for entries 1 and 2 . In entries 3-15 the acid was dried prior to use, see Supporting Information for full details; ${ }^{e} 0.7$ equiv $\mathrm{Ac}_{2} \mathrm{O}$ added. 
Table 2. Substrate scope. ${ }^{a}$

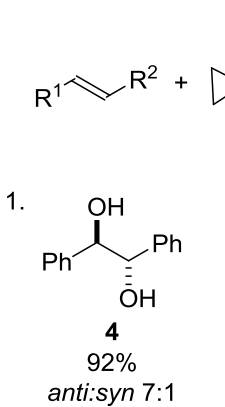

4.

$$
\overbrace{39 \%}^{\mathrm{OH}}
$$$$
\text { anti:syn 4:3 }
$$<smiles>O=C1OOC(=O)C12CC2</smiles>

$$
\underset{\text { 2. } 1 \mathrm{M} \mathrm{NaOH}, 60^{\circ} \mathrm{C}}{\stackrel{\text { 1. } \mathrm{AcOH}(2 \text { equiv) }}{\mathrm{CH}_{2} \mathrm{Cl}_{2}, 40^{\circ} \mathrm{C}}}
$$

2.

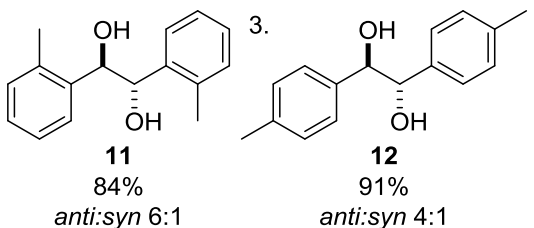

5.
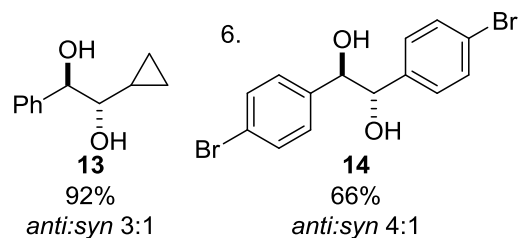

$$
\text { 7. }
$$

8.

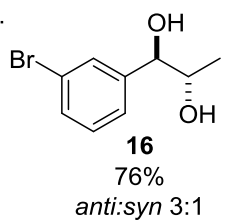

9.

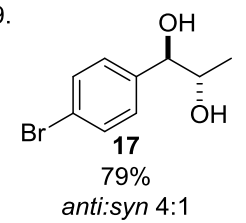<smiles>C[C@@H](O)C(O)c1cc([18OH])cc([N+](=O)[O-])c1</smiles>
anti:syn 2:1

13. $\mathrm{OH}$<smiles>COC[C@@H](O)C(O)c1ccccc1</smiles><smiles>C[C@]1(O)Cc2ccccc2C1O</smiles><smiles>OC1c2ccccc2C[C@@]1(O)P</smiles>

27

$83 \%$

anti:syn 10:1
11.

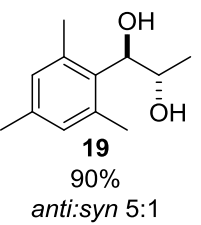

14. $\mathrm{OH}$

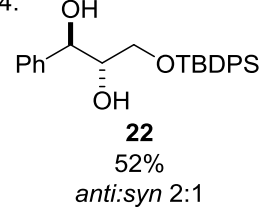

17.

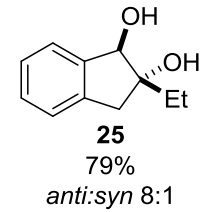

20.

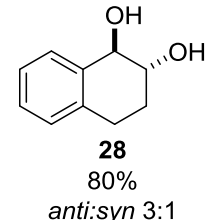

12.

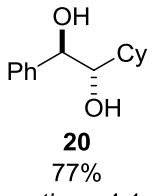

15.

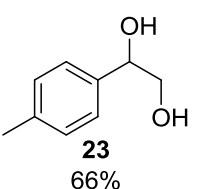

18.

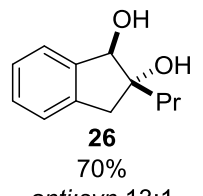

21.

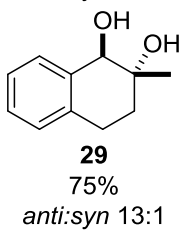

${ }^{a}$ Yields quoted are isolated yields. All reactions run in duplicate. Stereoselectivities were determined by ${ }^{1} \mathrm{H}$ NMR spectroscopy of crude reaction mixture.

From a mechanistic perspective, the addition of acetic acid to the dioxonium ion derived from a non-symmetrical alkene can occur at two possible carbon centers. In the reaction of 4-methyl styrene $\mathbf{3 0}$ with peroxide $\mathbf{1}$ in the presence of acetic acid the potential products are the isomeric esters 32 and 33 (Scheme 3). Interestingly, the addition of acetic acid occurs exclusively at the benzylic center (c.f. B Scheme 2) resulting in the bis-ester 32. Independent synthesis of 33 (see Supporting Information) and careful examination of the

crude reaction mixture showed that none of this bis-ester was formed to the detection limits of ${ }^{1} \mathrm{H}$ NMR spectroscopy. This shows that acetic acid addition is directed by electronic factors, consistent with an ionic mechanism under the acidic reaction conditions employed. This finding was supported by reaction of 2 substituted- $1 H$-indenes with malonyl peroxide 1 , which resulted in anti-diols with excellent selectivities (Table 2, entries 16-19; anti:syn $8: 1-13: 1)$. These reactions proceeded with complete control over the regiochemistry of acetic acid addition as shown by the relative stereochemistry between the benzylic oxygen and the 2substituent of the indene. This was also the case in the reactions of dihydronaphthalene derivatives (Table 2, entries 20 and 21).

\section{Scheme 3. Selectivity of acetic acid addition.}

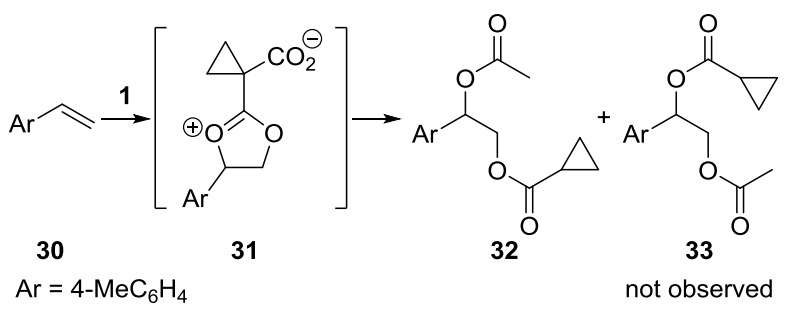

Examination of the crude mixture by ${ }^{1} \mathrm{H}$ NMR spectroscopy from the reaction of stilbene $\mathbf{2}$ and peroxide $\mathbf{1}$ prior to hydrolysis (under the optimized reaction conditions) showed none of the acid 10 was present, indicating that fortuitous water was not responsible for erosion in stereoselectivity. ${ }^{16}$ This reinforced our conclusions from the reaction conducted in the presence of acetic anhydride (Table 1, entry 10). Surprisingly, none of the expected diester 8 was observed, decarboxylation having occurred during the course of the transformation to deliver $\mathbf{3 4}$ as the major product (Scheme 4 ). Considering the proposed mechanistic course of the reaction we reasoned that erosion of selectivity therefore arose through formation of the 7-membered ring intermediate 6 which would lead to the syn-diol 3 upon hydrolysis. This was confirmed by isolation of 34 (anti:syn 31:1) and subjecting it to basic hydrolysis to give the anti-diol 4 (69\% from alkene; anti:syn 31:1). We therefore concluded that in the case of trans-stilbene, compromise in selectivity occurs primarily through formation of 6 rather than through $\sigma$-bond rotation in the intermediate 5 .

Further confirmation of regioselectivity in the addition of acetic acid came from the use of isotopically labeled acetic acid (Scheme 5). Reaction of alkene 35 with malonoyl peroxide $\mathbf{1}$ in the presence of labeled acetic acid gave the adduct $\mathbf{3 6}$ with two labels incorporated into the structure of the bis-ester. The relative stereochemistry of 36 was confirmed by single crystal X-ray analysis of the ${ }^{16} \mathrm{O}$ variant. Treatment of $\mathbf{3 6}$ with methylamine led to the anti-diol 37 where the label was incorporated exclusively into the benzylic center together with the amides $\mathbf{3 8}$ and $\mathbf{3 9}$. The location of the label in 37 was reinforced by oxidative cleavage of the diol under anhydrous reaction conditions ${ }^{18}$ to give labeled benzaldehyde $\mathbf{4 0}$ and unlabeled cyclohexanecarboxaldehyde 41. 
Scheme 4. Rationalizing selectivity levels observed.

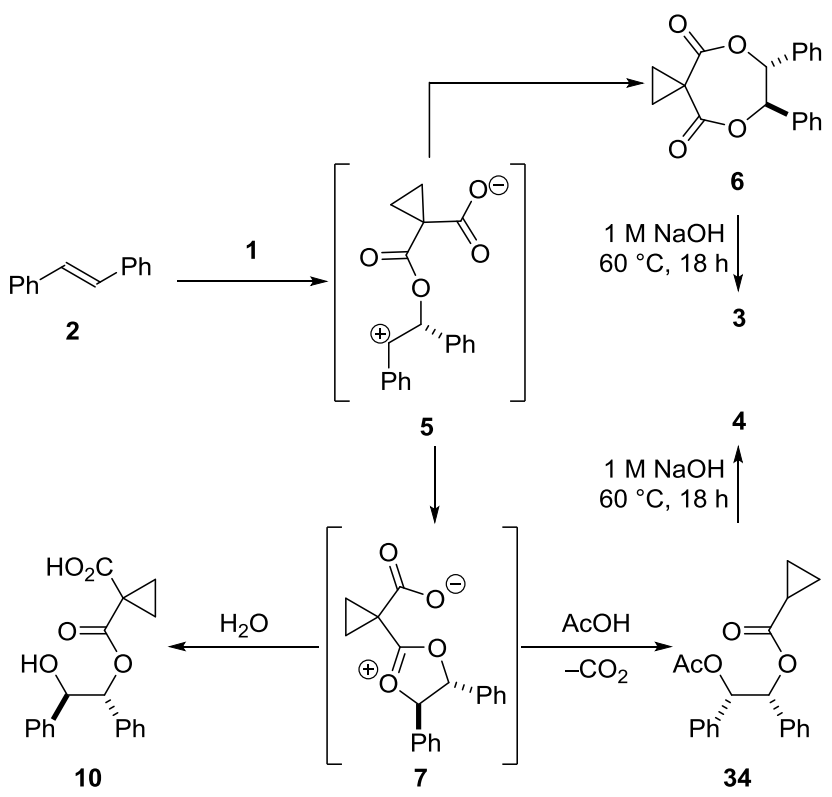

Scheme 5. Isotopic labeling experiments and X-ray structure of unlabeled 36.

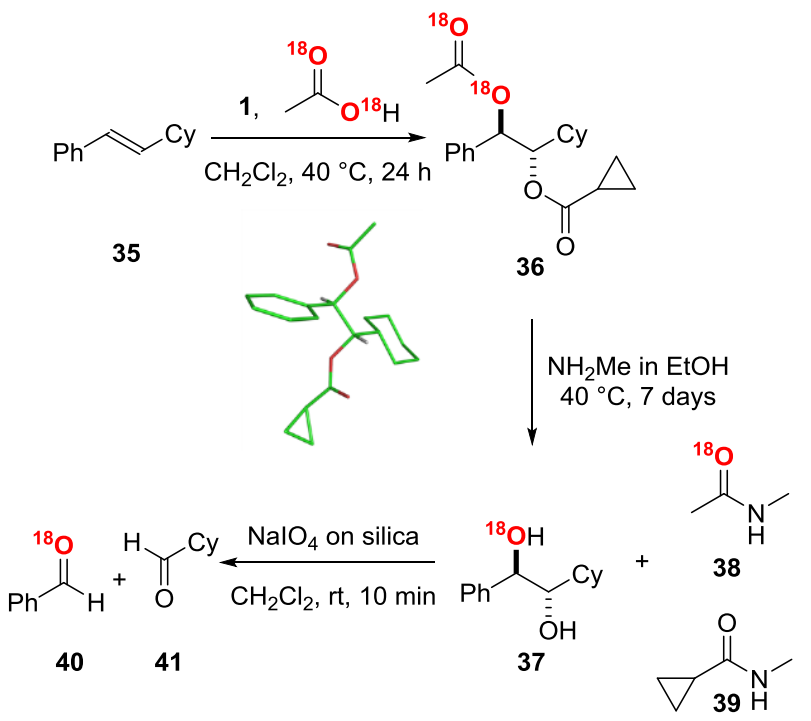

In summary, we have described a simple and effective method to alter the stereochemical course of the malonoyl peroxide mediated metal-free alkene dihydroxylation through judicious choice of additive. Reaction of an alkene and peroxide $\mathbf{1}$ in the presence of water leads to the syn-1,2-diol, whereas use of dry acetic acid delivers the anti-1,2-diol. This powerful discovery arose through an intimate understanding of the mechanistic course of the reaction to effectively intercept an intermediate to deliver a complementary diastereoisomeric product using the same reagent. Ring opening of the dioxonium intermediate proceeds with good regio- and stereoselectivity and bodes well for the development of additional bond forming reactions. Development of methods involving alternative nucleophiles is ongoing and will be reported in due course.

\section{Supporting Information}

Analytical data, experimental procedures and NMR spectra for all compounds reported. This material is available free of charge via the Internet at http://pubs.acs.org.

\section{AUTHOR INFORMATION}

\section{Corresponding Author}

*Nicholas.Tomkinson@strath.ac.uk

\section{ACKNOWLEDGMENT}

The authors thank the EPSRC, GlaxoSmithKline and University of Strathclyde for financial support and the EPSRC Mass Spectrometry Service, Swansea for high-resolution spectra.

\section{REFERENCES}

(1) Kolb, H. C.; VanNieuwenhze, M. S.; Sharpless, K. B. Chem. Rev. 1994, 94, 2483

(2) (a) Bataille, C. J. R.; Donohoe, T. J. Chem. Soc. Rev. 2011, 40, 114. (b) Asghar, S. F.; Lewis, S. E. Annu. Rep. Prog. Chem., Sect. B: Org. Chem. 2011, 107, 34. (c) Christie, S. D. R.; Warrington, A. D. Synthesis 2008, 1325.

(3) Rawling M. J.; Tomkinson, N. C. O. Org. Biomol. Chem. 2013, 11, 1434.

(4) For selected recent examples of novel methods for formation of the 1,2-diol functionality see: (a) Dornan, P. K.; Wickens, Z. K.; Grubbs, R. H. Angew. Chem. Int. Ed. 2015, 54, 7134. (b) Monaco, M. R.; Prévost, S.; List, B. Angew. Chem. Int. Ed. 2014, 53, 8142. (c) Aciro, C.; Davies, S. G.; Kurosawa, W.; Roberts, P. M.; Russell, A. J.; Thomson, J. E. Org. Lett. 2009, 11, 1333 .

(5) Usui, Y.; Sato, K.; Tanaka, M. Angew. Chem. Int. Ed. 2003, 42, 5623.

(6) Katsuki, T.; Sharpless K. B. J. Am. Chem. Soc. 1980, 102, 5974.

(7) Zhang, W.; Loebach, J. L.; Wilson, S. R.; Jacobsen E. N. J. Am. Chem. Soc. 1990, 112, 2801

(8) Tu, Y.; Wang, Z.-X; Shi, Y. J. Am. Chem. Soc. 1996, 118, 9806.

(9) (a) Iida, T.; Yamamoto, N.; Matsunaga, S.; Woo, H.-G.; Shibasaki, M. Angew. Chem. Int. Ed., 1998, 37, 2223. (b) Vogl, E. M.; Matsunaga, S.; Kanai, M.; Iida, T.; Shibasaki, M. Tetrahedron Lett. 1998, 39, 7917 (c) Matsunaga, S.; Das, J.; Roels, J.; Vogl, E. M.; Yamamoto, N.; Iida, T.; Yamaguchi, K.; Shibasaki M. J. Am. Chem. Soc. 2000, 122, 2252.

(10) Schmidt, V. A.; Alexanian, E. J. Angew. Chem. Int. Ed. 2010, 49, 4491.

(11) Giglio, B. C.; Schmidt, V. A.; Alexanian, E. J. J. Am. Chem. Soc. 2011, 133, 13320

(12) Prévost, C. Compt. Rend. 1933, 196, 1129.

(13) For recent reports which develop the Prévost reaction see: (a) Emmanuvel, L.; Shaikh, T. M. A.; Sudalai, A. Org. Lett. 2005, 7, 2250. (b) Zhong, W.; Yang, J.; Meng, X.; Li, Z. J. Org. Chem. 2011, 76, 9997. (c) Fujita, M.; Wakita, M.; Sugimura, T.; Chem. Commun. 2011, 47, 3983. (d) Zhong, W.; Liu, S.; Yang, J.; Meng, X.; Li, Z. Org. Lett. 2012, 14, 3336.

(14) (a) Griffith, J. C.; Jones, K. M.; Picon, S.; Rawling, M. J.; Kariuki, B. M.; Campbell, M.; Tomkinson, N. C. O. J. Am. Chem. Soc. 2010, 132, 14409. (b) Picon, S.; Rawling, M.; Campbell, M.; Tomkinson, N. C. O. Org. Lett. 2012, 14, 6250. (d) Jones, K. M.; Tomkinson, N. C. O. J. Org. Chem. 2012, 77, 921 .

(15) For use of peroxide $\mathbf{1}$ in the oxidation of aromatic rings see: Dragan, A.; Kubczyk, T. M.; Rowley, J. H.; Sproules, S.; Tomkinson. N. C. O. Org. Lett. 2015, 17, 2618.

(16) Rawling, M. J.; Rowley, J. H.; Campbell, M.; Kennedy, A. R.; Parkinson, J. A.; Tomkinson, N. C. O. Chem. Sci. 2014, 5, 1777.

(17) Woodward, R. B.; Brutcher, F. V. J. Am. Chem. Soc. 1958, 80, 209.

(18) Zhong, Y.-L.; Shing, T. K. M. J. Org. Chem., 1997, 62, 2622. 


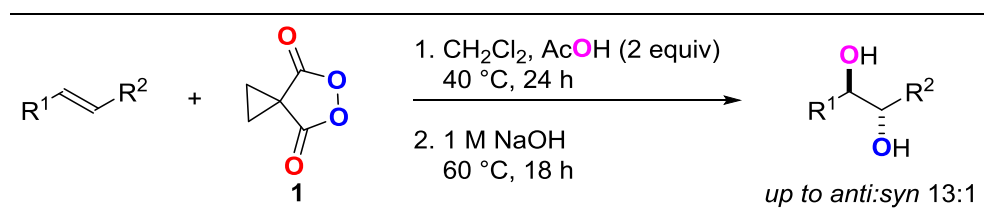

